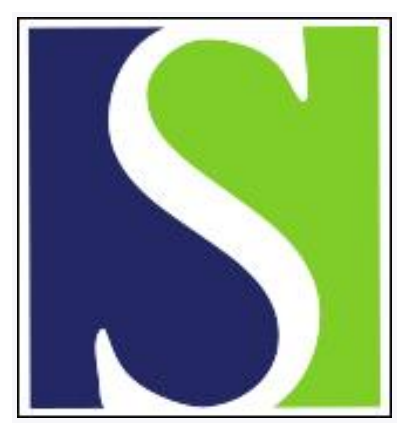

Scand J Work Environ Health 2005;31(3):169-178

https://doi.org/10.5271/sjweh.866

Issue date: Jun 2005

\title{
Multistate worklife expectancies
}

by Nurminen $M$, Nurminen $T$

Affiliation: Department of Epidemiology and Biostatistics, Finnish Institute of Occupational Health, Topeliuksenkatu 41 a A, FIN-00250 Helsinki, Finland. markku.nurminen@ttl.fi

The following articles refer to this text: 2007;33(3):161-164;

2008;34(2):83-95; 2020;46(1):77-84; 2021;47(1):5-14;

2021;47(7):540-549

Key terms: demography; disability; labor force activity; Markov model; multistate life table; regression methodology; retirement; review; statistics in society; unemployment; worklife expectancy

This article in PubMed: www.ncbi.nlm.nih.gov/pubmed/15999568 


\title{
Multistate worklife expectancies
}

\author{
by Markku Nurminen, PhD, ${ }^{1}$ Tuula Nurminen, DrPH ${ }^{1}$
}

\begin{abstract}
Nurminen M, Nurminen T. Multistate worklife expectancies. Scand J Work Environ Health 2005;31(3):169-178.
This communication reviews the demographic concept of worklife expectancy and draws the epidemiologists' attention to its usefulness in occupational health research and pension policy making. The distinctions between different analytic approaches to the quantification of expected workforce status and mobility are pointed out. A recently developed multivariate large-sample regression method for the analysis of worklife tables is placed into the general context of life tables. Given aggregated data from multiple cross-sectional or longitudinal population surveys, a multistate regression model can be used to estimate consistently marginal probabilities that a person is in a given work-health state or transition probabilities between the states and, thereby, worklife expectancies. The methodology is illustrated through the application to data from Finnish population statistics on employment, disability, retirement, and mortality. The paper closes with a discussion of the methodological issues and empirical findings on pension policy in Finland.
\end{abstract}

Key terms demography; disability; labor force activity; Markov model; multistate life table; regression methodology; retirement; review; statistics in society; unemployment.

The life table is a well-established statistical tool in actuarial science, demography, epidemiology, and biostatistics (1). In occupational health epidemiology, the cohort life table technique has been applied in the past to, for example, the survival analysis of groups of male workers after exposure to anthophyllite asbestos dust (2) and carbon disulfide vapor (3). The application of life table techniques to the study of labor force status and mobility was first suggested by Hoem (4) and carried out with data on labor force movements by Hoem \& Fong (5) to construct a worklife table for the Danish population. They computed estimates of the expected duration of worklife, or worklife expectancy, by age and separately for both genders. A life table can be constructed, for example, for a fixed group of people who share a membership-defining event (the cohort), such as entry into the workforce. For a stratified analysis, the cohort can be divided into particular subgroups specified by additional characteristics, for example, level of education (6), race (7), marital status, number of children, and occupation (8). Because of their many uses and their direct implications in various aspects of social planning, ordinary life tables and worklife tables have been constructed, and related expectancies have been calculated for several national population health surveys, for example, in the United States $(7,8)$, The Netherlands (9), Australia (10), and Finland (11-13).

Worklife and related expectancies are conceptually the same as health expectancies, both being an expected occupation time; the difference is that the former occurs in the context of labor force activity rather than in health statistics. Consequently, similar methods of analysis can be used in both fields. The goal of writing this paper was dual. The main objective was to introduce the notion of worklife expectancy to professionals who work in various health fields, but who may not be well versed in applied statistics. The brief treatise of the subject in the next section involves specified terminology, but is methodological rather than theoretical. An associated objective was to discuss distinctions between the different analytic approaches to the estimation of worklife expectancies and, specifically, to place a recently developed large-sample regression analysis method $(14,15)$ into the general context of survey methodologies. The novel method regards life history as a random process and is based on a Markov chain ${ }^{2}$ for discrete time-aggregated cohort data. Such modeling gives a more realistic characterization and a detailed analysis

1 Department of Epidemiology and Biostatistics, Finnish Institute of Occupational Health, Helsinki, Finland.

2 A stochastic process such that the conditional probability for the (work-health) state at any future time, given the present state, is unaffected by any additional information on the past history of the sequence of random variates.

Correspondence to: Dr Markku Nurminen, Department of Epidemiology and Biostatistics, Finnish Institute of Occupational Health, Topeliuksenkatu 41 a A, FIN-00250 Helsinki, Finland. [E-mail: markku.nurminen@ttl.fi] 
of labor force dynamics when compared with the frequency-based methods used traditionally in studies of health expectancies (16). The secondary objective was to present a recent application of the regression method to the estimation of worklife expectancies in Finland (11-13) and to discuss the implications of the main results regarding workforce activity in Finnish society.

\section{Worklife table methodologies}

\section{Construction of the worklife table and estimation of worklife expectancy}

Worklife expectancy is a statistical construct modeled on the ordinary life table $(17,18)$, and it analyzes and projects both labor force participation and trends and patterns in the rates of disability, retirement, and mortality. Labor force participation rates were originally expressed as age-specific proportion-type rates, for example, for being in different work ability and health states. This situation led to the construction of prevalence-rate worklife tables, usually based on the work of Sullivan (16). These much-applied conventional techniques are limited to data collected at a single point in time or from an isolated labor force survey. The prevalence rates can be used as estimates of the corresponding marginal probabilities that define the distribution of state occupancy. Mathers (19) noted that "The problems with Sullivan's method arise not because it uses prevalence and mortality data averaged over all health states, but because the data it uses are dependent on past conditions in the population [p 190]". Therefore, Sullivan's method for calculating period health expectancy does not produce a "pure" cross-sectional indicator derived from the current health transition rates summarizing the health experience of a population at a point in time (19). The standard period worklife expectancy (eg, at the age of 25 years for Finnish men in 2005) is a pure cross-sectional indicator in the sense that it gives the

Table 1. Observed marginal and transitional frequencies for the Finnish male cohort aged 50 years in 1985, of the four states, first = "employed", second = "disabled", third = "other alive", and fourth = "deceased" [Source: Nurminen et al (12)].

\begin{tabular}{|c|c|c|c|c|c|}
\hline \multirow{2}{*}{$\begin{array}{l}\text { Age }=50 \text { years } \\
(1985)\end{array}$} & \multicolumn{4}{|c|}{ Age $=57$ years $(1992)$} & \multirow{2}{*}{$\begin{array}{c}\text { Marginal } \\
\text { (column) } \\
\text { total }\end{array}$} \\
\hline & $\begin{array}{l}\text { First } \\
\text { state }\end{array}$ & $\begin{array}{l}\text { Second } \\
\text { state }\end{array}$ & $\begin{array}{l}\text { Third } \\
\text { state }\end{array}$ & $\begin{array}{l}\text { Fourth } \\
\text { state }\end{array}$ & \\
\hline First state & 41 & 43 & 16 & 17 & 117 \\
\hline Second state & 10 & 32 & 60 & - & 102 \\
\hline Third state & - & - & 9 & - & 9 \\
\hline Fourth state & - & - & - & 2 & 2 \\
\hline Marginal (row) total & 51 & 75 & 85 & 19 & 230 \\
\hline Distribution & 0.22 & 0.33 & 0.37 & 0.08 & 1.00 \\
\hline
\end{tabular}

expectation of worklife for people who experience, at each age of their lives, the risk of moving outside the workforce observed for Finnish men of that age in 2005. However, a simulation study indicated that Sullivan's method provides acceptable estimates of period health expectancy if the changes in transition rates over a reasonably long period are smooth and fairly regular (20). In particular, the repeated application of the method can provide good estimates of trends in health expectancy. But, as Davis et al (14) pointed out, "By definition the Sullivan method as described cannot supply these estimates [of cohort health expectancies], except in so far that a period measure is a surrogate for the analogous cohort quantity [p 1099]."

Worklife tables are also concerned with the dynamics of labor force participation, that is, with state-to-state movements. The transition rates are expressed as occurrence-exposure rates; that is, the ratios of the number of occurrences (typically moves from one work-health state to another) to the total amount of time that the persons occupied the first state (person-time exposed to the risk of transition). In demography, the term incrementdecrement worklife table is used $(21,22)$. In epidemiology, this notion is called a multistate worklife table (23), which recognizes several states, as well as multiple entries to and exits from these states, for example, within a given age interval. In addition to reversible transitions between "nonabsorbing" states, the multistate model can include terminal states. The occurrence-exposure rates can be regarded as the estimates of the corresponding transition intensities that generated the aggregated data recorded in the worklife table. There are numerous methods for transforming the occurrence-exposure rates to the corresponding transition probabilities, and thereby to worklife expectancies (24). For the estimation of these parameters, data are collected from sequential (cross-sectional) population surveys (eg, 25).

As an illustration, table 1 presents transition frequencies for a subcohort of Finnish municipal workers aged 50 years in 1985 with four mutually exclusive and exhaustive work-health states: (i) "employed", (ii) "disabled", (iii) "other alive", and (iv) "deceased" (12). In 1992 , the marginal distribution of the relative frequencies of the respective states was $22 \%, 33 \%, 37 \%$, and $8 \%$, respectively. From 1985 to 1992, there were transitions from the first state to the second through the fourth, from the second state to the first and third states, but no transitions from the third state.

For a worker of a given initial age, worklife expectancy is the future time that the person is expected to spend in employment earning wages and benefits provided that the prevailing patterns of mortality, morbidity, and disability remain unchanged. Depending on whether cross-sectional or longitudinal data are available, current (short period) or cohort life tables can be 
constructed. Usually, only cross-sectional data can be obtained, and the period worklife expectancies are estimated for the given years.

There appears to be some variation in the definition of worklife expectancy. The United States (US) Bureau of Labor Statistics considers two states of labor activity, "active" and "inactive" (7). Their definition of worklife expectancy and the previous Danish usage (17) apply to "active" persons; the term "active" was simply taken to refer to an individual who is in the labor force, but it did not imply that the person is employed. An "inactive" person was defined as an individual who is not in the labor force for whatever reason. In the Finnish application (12), the adopted definition of worklife expectancy was the expectation of the time spent in employment, and the estimation of worklife expectancy was performed jointly with the expected times spent in the related states of "disabled" or "other alive" (ie, outside employment for any other reason than disability). The latter definition allows the consideration of the effects of promoting work ability on worklife expectancy in the employed population. However, it hinders the comparison of the Finnish estimates of worklife expectancy, for example, with the earlier published US figures (7). In principle, the Finnish worklife expectancy estimates could be compared with the more recent US estimates of worklife expectancy for a population with three states, "employed", "unemployed", and "inactive" (8). However, the demographic characteristics of the two countries differ, for example, with respect to educational level and racial composition so that direct comparisons would be misleading or uninformative.

\section{Markov process model of worklife tables}

Given aggregated data on labor force activity generated by a Markov process with a continuous time, a method was developed for the analysis of worklife tables by Hoem (17). The general Markov property assumes that the future transition rates depend only on the state an individual currently occupies and not on any previous states of origin. The Markov model assumes implicitly that all sources of individual-level heterogeneity are explained by the covariates that are entered in the analysis of worklife tables (26). The origin-independence and time-homogeneity specifications are almost surely not valid for extended time periods. Therefore, the Markov regression models should be estimated using data on (piecewise) short age intervals. Land et al (26) chose 1-year age intervals. To achieve piecewise independence of the transition rates of the state of origin in the case of wider age intervals, Davis et al (15) developed a stochastic interpolation method. The procedure hinges on the Markov condition, which provides a recursion formula that connects multiyear to 1-year transition probabilities. Even so, the specification of the Markov chain model in itself is often a rough approximation of empirical data, accepted for convenience with the tacit assumption that the model is sufficiently realistic for the empirical application at issue.

\section{Model-based versus nonmodel-based analysis}

Traditional methods to describe and explain the population distribution of states and transitions between states, such as multistate life tables, are often not based on a parametric model. The relative frequency approach relies on age group or other subgroup comparisons and calculates the transition probabilities from the average behavior of the samples at each age (27). Due to substantial stochastic variability in the transition rates from one age interval to another, the techniques do not permit the estimation of life tables with many covariates, even if relatively large samples are available for the study of flows into and out of the labor force (26). Moreover, when the multistate life tables of subgroups are compared, other covariates are not kept constant, so differences among subgroups in life expectancies capture the total rather than the partial effect of the grouping variate.

The conventional model-based (or parametric) analysis of multistate life tables applies the estimated parameterized transition probabilities to the state space at the aggregate level by cross-classifying all the covariates. In this aggregate-level analysis, the basic statistical unit is a group, and the sizes of groups are updated, usually by matrix multiplication. Several empirical studies have used this method, for example, with active life expectancy (28), retirement inequality (29), and labor inequality (30). However, with an increasing number of covariates, the number of cells increases very fast and leads to vanishing cell frequencies. In the approach of Davis et al $(14,15)$, the explicit modeling of the probabilities as a function of relevant covariates enables one to alleviate problems of small cell sizes so that the number of covariates can be fairly large. This approach is meant for the analysis of panel or cohort data when the numbers are reasonably large, but frequencies of 10 or more in nonabsorbing cells should be sufficient.

In an individual-level analysis, the basic statistical unit is an individual, and the characteristics of individuals, and links between them, are updated, usually by a Monte Carlo simulation that randomly generates values for uncertain variates over and over to simulate a model. Based on a parametric model, this technique simulates individual-level transitions of a population, which are then aggregated to the population distribution (31). The computerized modeling technique has been applied to analyze active life expectancies (32). Although these computer-intensive techniques have many advantages 
(33), the computational complexity and burden has thus far hindered their routine application, for example, in the field of occupational health research.

\section{Multistate models for worklife tables}

The first multistate model for a worklife table based on a Markov chain was proposed by Hoem (4) and applied to the calculation of a worklife table of the whole Danish population for the years 1972-1974 (5). This was followed by a study in the United States (US) for 1972 (21). Later US studies were conducted for the years 1992-1993 (34), 1997-1998 (7), and 1992-2000 (8). In the US studies, the applied methods assumed an increment-decrement model or a Markov process model of labor force activity. More recently, worklife expectancies were estimated from survey data on municipal workers $(11,12)$ and for the entire population of Finland, for 1980-2001, using census data on population sizes, mortality statistics, register data on disability, and labor force surveys on employment activity (13). These studies applied the method of Davis et al $(14,15)$, which uses a large-sample regression based on a multinomial model and its approximation by a multivariate normal distribution. The procedure gives estimates of marginal probabilities of being in a defined work-health state or transition probabilities between states. The Markov property was not required for the estimation of the worklife expectancies using marginal probabilities (14), whereas the estimation that uses transition probabilities was done according to the Markov assumption (15). The failure of the Markov condition would mean that the estimates are not statistically efficient, but that the method is still useable. When the Markov property does not hold, standard errors can be obtained using the method of Liang \& Zeger (35). The multinomial regression approach is suited to the analysis of discrete-time aggregated data that are usually produced by official statistical agencies. Different approaches have used a multinomial logistic or log-linear model with covariates built on a multistate life table or a Markov chain model (25, 26,36 ). Brunsdon \& Smith (37) used the same logistic transformation of the marginal probabilities (ie, the logarithmic transformation of the ratios of probabilities) as Davis et al (14). However, they used ARIMA (autoregressive integrated moving average) modeling, rather than weighted least squares, to estimate the model parameters.

Recently, Millimet et al (8) also used a logistic transformation to estimate transition probabilities and thereby to derive worklife expectancies. The multivariate regression model included economic and demographic variates that determine labor force participation rates. However, their method differs from the Markov chain method developed by Davis et al (15). The major difference, and the novelty of the Davis et al method, is that they first prove a theorem of the asymptotic normality of the empirical logarithmic transformations of the ratios of probabilities (log-ratios). The second step of this method is the estimation of the parametrized true log-ratios by weighted least squares. ${ }^{3}$ The method can only proceed in this way because it deals with a large number of persons. Millimet et al did not exploit the large number of people, and they used a standard package for maximizing the likelihood. In a sense, the method of Davis et al is a large sample version of logistic regression since it ends up with weighted least squares as opposed to solving nonlinear maximum likelihood equations by the Newton-Raphson procedure or some other numerical device. In the applications, the theorem allows for the treatment of statistical inferential questions concerning the Markov chain.

Regression methods have, however, previously been used also in the study of ordinary life tables $(9,38-40)$. The Heligman-Pollard (38) approach fits a regression model by ordinary least squares to the logistic transform of the age-specific risk of death. In this approach, the form of the regression model is determined a priori, whereas the approach adopted by Davis et al $(14,15)$ has the advantage that the model is determined by an exploratory analysis of the observed log-ratios. The method of Heathcote \& Higgins (9), which is a specialization of the Davis at al multistate approach to the case in which there are only two states (alive and dead), models the risk of death specific to both age and year and develops a large-sample weighted least squares technique for fitting mortality surfaces. These are parameterized measures of mortality indexed by age and year, whose random elements are generated by stochastic processes defined on the diagonals of the Lexis plane (41).

There are two basic approaches to constructing multistate worklife tables. Hoem \& Funck Jensen (42) argued from a mathematical statistics perspective that the proper starting point for the estimation of worklife tables is to specify a state space and a model for transition intensities, since the transition probabilities can be found, in principle, by solving the Kolmogorov differential equations, which play a central role in the analysis of Markov processes in a continuous time (1, p 114115). This is the case for the three-state labor force increment-decrement table with nondifferential mortality (5). In more complicated situations, one usually has

3 A method of fitting a mathematical form to data by minimizing the sum of squares of deviations between observed and fitted values. The applied model is nonlinear in the parameters, and the errors are normally distributed with constant variance. Therefore, the least squares estimates become equivalent to maximum likelihood estimates. 
to resort to approximation formulas (43) in order to produce the transition probabilities. From these probabilities one can subsequently compute other derived quantities, such as worklife expectancies.

On the other hand, many demographers and statisticians prefer to formulate their assumptions directly in terms of transition probabilities rather than defining transition intensities, which are interpreted as instantaneous hazard rates (44). Many of the methods available in demographic literature are based on various assumptions of the parametric form of the transition probabilities, usually polynomials in age or time. Unfortunately, this approach can be problematic, as it may lead to unrealistic results for the transition intensities induced by the modeling assumptions. The problems in that line of approach are not caused by the real-life phenomena studied or the complexity of the theory of Markov chains, but are produced by the technicalities of the methodology (42). Therefore, the modeling assumptions related to the parametric function of the transition probabilities should be regarded as a method of numerical analysis and should not be taken as part of the multistate model specification.

Given that proper data are available, the semi-parametric (proportional hazards) regression model (45) and its extensions can be applied in a straightforward manner to study transitions in multistate demographic models at an individual level. However, it is doubtful whether these models are very useful in traditional population projections. The problem is that retrospectively obtained life histories from cross-sectional surveys cannot readily be analyzed using a Cox regression without bias being introduced (46).

\section{Empirical results}

The results concerning the worklife expectancies for the entire Finnish population have been published in detail elsewhere (13). Here we give worklife expectancy estimates for Finnish men and women for selected 5-year age intervals and calendar-year periods (table 2). For each age and both genders, from 1981 to 2001, the worklife expectancies generally decreased. The change was substantial for the under 30-year-olds, no doubt partly due to the increased years of education. The patterns of worklife expectancies were similar for the men and women at young ages, although the numerical estimates were often discrepant. At older ages different trends appeared. For example, during 1981-2001, for the men 55 years of age, the worklife expectancy for employment to the age of 64 years declined from 4.7 to 3.9 years. On the other hand, for the women 55 years of age, the worklife expectancy stayed roughly constant, and the male figure was projected to fall below the initially lower female figure by 2006. For both genders, the deep economic recession of the early 1990s in Finland led to a sharp drop and then to a rebound in the probability of employment, with a consequent effect on expectancies.

A comparison between worklife and general life expectancies is of considerable interest for two reasons. First, there is a growing propensity towards early retirement in many western European countries, especially in Finland. Second, the Finnish population is rapidly aging. A quantification of life and worklife expectancies for men and women is presented in figures 1 a and $1 \mathrm{~b}$, respectively.

Although there was a greater increase in the male life expectancy (5.1 years) between 1981 and 2001 than in the female life expectancy ( 3.7 years), the future proportion of worklife declined slightly more for the men than for the women. While the male worklife expectancy at the age of 25 years, expressed as the percentage of future worklife to the statutory retirement age of 65 years, decreased by $4 \%$-units (from $75 \%$ to $71 \%$ ), the respective decline for the women was 3\%-units (from $70 \%$ to $67 \%$ ).

Table 2. Worklife expectancies (years in employment to the age of 64 years) of the Finnish population for selected years and ages, with projections for 2006 [Source: Nurminen et al (13)].

\begin{tabular}{|c|c|c|c|c|c|c|c|c|c|c|c|c|}
\hline \multirow{2}{*}{$\begin{array}{l}\text { Age } \\
\text { (years) }\end{array}$} & \multicolumn{6}{|c|}{ Men } & \multicolumn{6}{|c|}{ Women } \\
\hline & 1981 & 1986 & 1991 & 1996 & 2001 & 2006 & 1981 & 1986 & 1991 & 1996 & 2001 & 2006 \\
\hline 16 & 34.9 & 34.3 & 33.4 & 28.7 & 32.1 & 31.4 & 32.9 & 32.2 & 31.4 & 27.6 & 30.3 & 29.7 \\
\hline 20 & 33.2 & 32.8 & 32.0 & 27.8 & 31.0 & 30.5 & 31.0 & 30.5 & 29.9 & 26.6 & 29.2 & 28.7 \\
\hline 25 & 29.7 & 29.5 & 28.9 & 25.4 & 28.3 & 27.9 & 27.9 & 27.6 & 27.1 & 24.4 & 26.8 & 26.5 \\
\hline 30 & 25.0 & 25.9 & 24.9 & 21.9 & 24.4 & 24.1 & 24.0 & 23.9 & 23.5 & 21.3 & 23.5 & 23.4 \\
\hline 35 & 21.2 & 21.0 & 20.6 & 17.8 & 20.1 & 19.9 & 19.9 & 19.8 & 19.5 & 17.7 & 19.6 & 19.6 \\
\hline 40 & 16.7 & 16.6 & 16.1 & 13.7 & 15.7 & 15.5 & 15.6 & 15.5 & 15.3 & 13.8 & 15.5 & 15.5 \\
\hline 45 & 12.4 & 12.2 & 11.8 & 9.6 & 11.4 & 11.2 & 11.4 & 11.2 & 11.0 & 9.8 & 11.3 & 11.4 \\
\hline 50 & 8.3 & 8.1 & 7.6 & 6.0 & 7.3 & 7.2 & 7.3 & 7.2 & 7.0 & 6.1 & 7.3 & 7.4 \\
\hline 55 & 4.7 & 4.5 & 4.1 & 2.8 & 3.9 & 3.8 & 3.8 & 3.7 & 3.6 & 2.9 & 3.8 & 3.8 \\
\hline 60 & 1.9 & 1.8 & 1.6 & 0.9 & 1.3 & 1.4 & 1.2 & 1.2 & 1.2 & 0.8 & 1.2 & 1.3 \\
\hline
\end{tabular}


Life and worklife expectancies

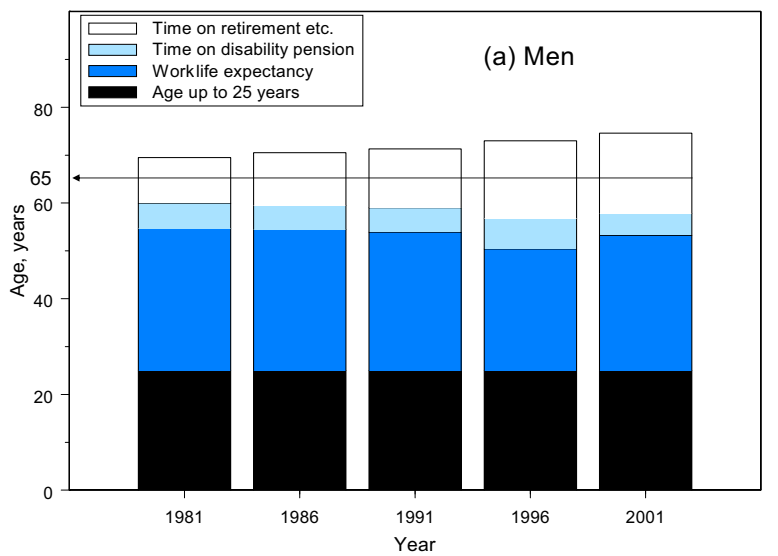

Life and worklife expectancies

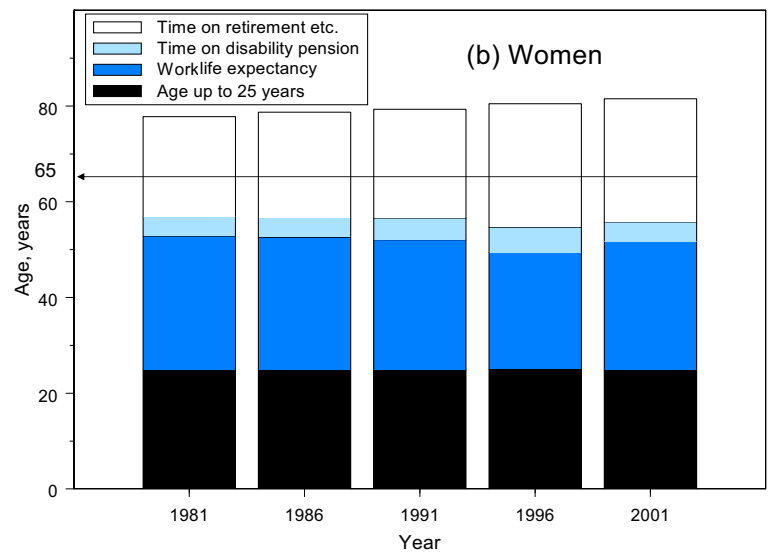

Figure 1. Life and worklife expectancies for the Finnish population according to 5-year intervals between 1981 and 2001, separately for the men (a) and women (b). The height of the bars stands for life expectancy (in years) divided into four successive periods: age up to 25 years, worklife expectancy at age 25 years, time on disability pension, and time on retirement or outside employment for any other reason than disability and retirement. The tacit assumption underlying this presentation is that there are no intermittent periods of employment, disability, or retirement. The line indicates the statutory retirement age of 65 years in Finland.

\section{Discussion}

\section{Methodological issues}

Davis et al $(14,15)$ developed a multivariate model for analyzing longitudinal aggregated data. The modeling approach uses modern, sophisticated methodologies to estimate the probabilities of being in a given workhealth state and movements between the states. This development makes possible the handling of multiple concomitant variates that affect the probabilities.

When applied to the total Finnish population data, the new multistate regression method provided estimates of the expected time that a person will be actively employed, disabled, in the state "other alive" (eg, retired), or dead from 15 to 64 years of age, under current conditions (13). The worklife expectancies and related expected sojourn times in the specified work-health states are readily interpretable by epidemiologists and other professionals working in health fields. [For other summary measures of population health, such as health gaps, see Nurminen (47).]

The multivariate large-sample regression method of Davis et al $(14,15)$ is, in important respects, advantageous over methods that have been previously applied to the study of multistate life tables (eg, 26, 42, 48, 49). First, Davis et al base their discussion on stochastic processes in a discrete-rather than continuous-time and argue that this procedure makes the modeling of probabilities easier. Discrete-in-time models are less demanding with respect to proficiency in mathematics, and their implementation is simpler. For example, the parametrization, and hence simultaneous dependence on age and time, is determined by an exploratory analysis of the observed logarithmic transformations of the ratios of transition rates, and not determined beforehand.
The final transition probabilities are estimated by a weighted least squares (essentially estimating equations) method using standard regression procedures. The regression formulation is very familiar and widely understood, which makes the method more immediately accessible to a broader audience. In the marginal frequency case the multinomial frequencies are autocorrelated and the standard errors are calculated using the method of Liang \& Zeger (35). An important result with the method of Davis et al (15) is that the log-ratios of the transition probabilities at different ages are asymptotically independent if the process is Markov. This useful finding means that, when samples are large, one can ignore autocovariances. On the other hand, continuousin-time models provide information at all times, and they more clearly show the qualitative effects that can be expected when the value of an explanatory variate is changed. The alternative Markov regression models with log-ratio transformations of the transition probabilities are generally not applicable when the number of transient states is greater than two (26). In contrast, the method of Davis et al allows the modeling of a larger number of initial states. Finally, the explicit modeling of the probabilities as a function of relevant covariates enables one to alleviate problems of small cell sizes. It follows that the number of covariates entered in the model can be fairly large. In the Finnish application (13), for example, the national data consisted of a fourdimensional array of 8800 frequencies indexed by age, calendar year, work-health status, and gender. In addition to linear, quadratic, or cubic terms in age and linear terms in time, as well as their interactions, the model included statistical terms (such as normal density and continuous piecewise linear surface) to describe the characteristics of the data. The parametric model 
permitted the estimation of 27 parameters for men and 30 parameters for women. This model was similar to the regression model of mortality applied in the study of Heathcote \& Higgins (9) for ordinary life tables. The method of Davis et al is more general than the regression methods that have been presented previously in that it models the probabilities specific to both age and year and their product term simultaneously. Polynomial interpolation in the time dimension (50) and in the age dimension (graduation) is well known, but fitting a twodimensional polynomial with interaction to the Lexis surface is novel.

One aim of this paper was to outline the different methodologies available for the calculation of worklife expectancies, given aggregated data on worklife activity. The choice of analytic technique will involve at least four considerations, namely, the objectives of the study (eg, estimation or projection of workforce dynamics), the type of data that are available (eg, marginal or transition frequencies for the cohort), the properties of the methodological approach (frequency- or model-based method), and the weighing of the technique's computational complexity and burden (eg, simple iterative process or computer-intensive simulation). Given aggregated data from multiple cross-sectional surveys of a population, the multistate worklife table methodologies with large-sample regression modeling offer a versatile approach for a detailed analysis of the progression of worker's occupational career and health.

\section{Empirical findings on pension policy in Finland}

In the Finnish study (13), we applied the worklife expectancy indicators to the official statistics of Finland to determine the duration that a worker spends in employment, on disability pension, or on retirement pension or otherwise outside employment. This quantification was done separately for both genders in the period 1980-2001, together with a projection for 2006. The projection gives the estimated worklife expectancy if the current labor market conditions prevail. In future analyses, predictive covariates - such as employment rate, number of hours worked, change in production compared with that in a previous year, increased hours of overtime work - can be entered into the multivariate regression model to improve the estimation. This model can then be used to predict the impact that potential interventive measures have on the development of the labor market.

Two aspects of gender differences in longevity deserve consideration. First, these differences may partly be explained by the biological protection conferred on women. However, in advanced industrialized countries like Finland, this gap may eventually start to narrow as women begin to take on more "male" behavior (eg, smoking, heavy drinking, and increased workload) (51). In fact, the vital statistics of Finland show that, in 19661980, the female-male difference in life expectancy at birth widened, whereas for the past 20 years the gap has narrowed from 8.7 to 6.6 years. Second, even though women outlive men, they tend to live in a poorer state of heath (52) or with a higher prevalence of functional disability than men, when measured by indicators such as self-perceived ill health that do not necessarily imply work disability (6).

Hytti (53) studied active and retirement life expectancy for in the Finnish population over the period 19701993 using the prevalence-rate method (16). Her central finding was that the increase in life expectancy had almost exclusively lengthened the time spent in retirement. Early retirement concentrated increasingly into the age group of 55-64 years. Hytti concluded that prolonging active life expectancy at birth by 1 year per decennium from 1990 to 2020 would nearly halve the increase in the pensioner population when it is compared with the growth projected on the basis of the 1990 prevalence rates.

According to the Finnish Centre for Pensions (54), the disability to work continues to be the most common reason for persons retiring on an earnings-related pension in Finland, followed by old-age pensions and unemployment pensions. Disability rates increased in the early 1990s and attained peak values in 1994, after which they started to decline. There are several reasons for this development. [See, eg, Gould \& Nyman (55).] The proportion of people on disability pension in the population decreased after the recession in Finland in 1990-1994. In addition, the proneness to apply for a disability pension and the number of new disability pensions decreased during the 1990s, although, at the end of the decade, both again started to increase slowly. The inclination towards early retirement has been observed to increase when a person approaches the age that permits leaving the workforce. However, this trend continues only up to 60 years of age, after which it declines or levels off (56). The number of those drawing an individual early-retirement pension grew rapidly at the end of the 1980s and in the beginning of the 1990s when this pension was introduced in the governmental and municipal sectors. Toward the end of the 1990s a large number of individual early-retirement pensions changed to old-age pensions because the early retirement pensioners of the late 1980s reached retirement age. This phenomenon was reflected in the Finnish data on the "other alive" persons, who included people on ordinary or early old-age pensions (13).

In Australia, estimates of health expectancies based on survey data supported the view that, depending on age, two-thirds or more of the increase in female life 
expectancy over the decade 1988-1998 was spent in the disabled state (41). The situation was worse for older men (ie, aged 60 years and over), for whom all of the increased years of expected life were estimated to be spent in a disabled state.

In Finland, a significant proportion of the "other alive" group comprised the unemployed (13). Finland has suffered from high unemployment for years. According to the Labour Force Survey of Statistics Finland (http://www.stat.fi/til/tyti/. Accessed on March 10, 2005.), there were 249000 unemployed persons $(9.8 \%$ of the workforce) in January 2005, but over the last 10 years the unemployment rate has been considerably higher (16\% in 1993). As more unemployed and retired people are being supported by fewer working people, future economic success depends on how society can cope with the high level of the economic dependency ratio, that is, the ratio of unemployed persons and those outside the labor force to the number of employed persons. The countries that will do worst are those in which the population is aging the fastest and those with governments that have made the most optimistic promises, for example, regarding the reduction of unemployment (57). Here we can look mainly at Europe, and especially at Finland, to find this combination of problems.

The Finnish population is aging earlier and more rapidly than that of most other European Union countries (58). With an increasing proportion of older people in the Finnish population, to keep the pension costs in check, retirement schemes may need to be adjusted to increased longevity (59).

According to the macroeconomic forecast of the Bank of Finland, the employment rate ${ }^{4}$ should be about $67.7 \%$ in 2005 (60). In January 2005, the employment rate was $65.3 \%$ (The Labour Force Survey of Statistics Finland. http://www.stat.fi/til/tyti/. Accessed on March 10,2005 .). It is calculated that the unused potential labor force of Finland totals 200 000-300 000 persons (employed workforce 2.55 million). To increase the employment rate to about $75 \%$, the number of employed would need to increase by about 250 000. The officially held target of the Finnish government, to increase employment by at least 100000 persons (an increase in the employment rate to $68.8 \%$ ) by the year 2007 may prove to be extremely difficult to attain. However, it has been predicted that a $70 \%$ employment target is insufficient to prevent the economic dependency ratio from soaring after 2010 (61). Another conclusion of the study was that increasing the average age of retirement would improve the employment rate and economic dependency ratio.

According to the Organisation for Economic Co-operation and Development (62), disability pensions should be awarded more restrictively in Finland in order to avoid the risk of an increased use of disability schemes. Furthermore, reforms aimed at raising the retirement age are urgently needed. In 2003, the average effective retirement age was below 59 years (63). Accordingly, the aim of the Finnish government is to raise the retirement age. In the strategic vision of the Ministry of Social Affairs and Health, the following strategic objectives were set (64): people stay at work for 2-3 years longer than they do at present, the general functional capacity of the population improves, and work is more attractive and promotes well-being. To achieve the first objective, in 2003, the Parliament passed new legislation for the private sector that introduces a flexible statutory earnings-related retirement age between 62 to 68 years with strong incentives to remain at work. Most importantly, pension entitlements will be linked to lifetime earnings, and the increasing life expectancy will be allowed to affect retirement age. Furthermore, the individual early retirement pension (a special disability pension for aging employees) and the unemployment pension will be abolished. Thus there will be only two routes to early retirement: the ordinary disability pension and the earnings-related partial disability pension. The elimination of other early retirement pension schemes will probably increase the number of disability pensioners. On the other hand, the pension reform will probably improve the employment rate among the aging labor force. All these measures, which came into effect in 2005, are geared at providing more incentives in the future for people to remain in the labor force over a longer period.

In conclusion, there exists a risk that reasonable economic growth will not be realized in Finland, because employed persons will, in the coming years, leave worklife in great numbers. The new working population entering the labor market will not suffice to compensate for the persons who retire, who will constitute an increasing proportion of the aging population. These trends can lead to a serious social and economic outlook for Finnish society because of the looming labor force shortage that can undermine the sustainability of a welfare state unless interventive policy measures are able to reverse the development and make the present forecasts not come true.

"Employment rate" means the share of employed persons in the working-aged population. The working-aged population is traditionally defined as the 15- to 75-year-old population. In practice, the working-aged population is often restricted to the age range 15-64 years because most people older than 64 years in most developed countries are retired. Employed persons in Finland include all those who had worked at least 1 hour during the week that the Labour Force Survey was conducted by Statistics Finland. 


\section{Acknowledgments}

We thank Brett Davis and Christopher Heathcote for their insightful comments.

\section{References}

1. Chiang CL. Introduction to stochastic processes in biostatistics. New York (NY): John Wiley \& Sons, Inc; 1968.

2. Nurminen M. A study of the mortality of workers in an anthophyllite asbestos factory in Finland. Work Environ Health 1972;9:112-8.

3. Nurminen M. Survival experience of a cohort of carbon disulfide exposed workers from an eight-year prospective follow-up period. Int J Epidemiol 1976;5:179-85.

4. Hoem JM. Point estimation of forces of transition in demographic models. J Roy Stat Soc Ser B 1970;33:275-89.

5. Hoem JM, Fong MS. A Markov chain model of working life tables, report no 1: a new method for the construction of tables of working life. Copenhagen: Copenhagen University; 1976. Copenhagen University Laboratory of Actuarial Mathematics, Working Paper No 2.

6. Valkonen T, Sihvonen AP, Lahelma E. Health expectancy by level of education in Finland. Soc Sci Med 1997;44:801-8.

7. Ciecka J, Donley T, Goldman J. A Markov process model of work-life expectancies based on labor market activity in 199798. J Leg Econ 2000;9:33-68.

8. Millimet DL, Nieswiadomy M, Ryu H, Slottje D. Estimating worklife expectancy: an econometric approach. J Econ 2003;113:83-113.

9. Heathcote CR, Higgins T. A regression model of mortality, with application to the Netherlands. In: Tabeau E, van den Berg Jets A, Heathcote CR, editors. Forecasting mortality in developed countries: insights from a statistical, demographic and epidemiological perspective. Dordrecht (The Netherlands): Kluwer Academic Publishers; 2001. p 59-82.

10. Davis BA, Heathcote CR, O'Neill TJ, Puza BD. The health expectancies of older Australians. J Popul Res 2003;20:169-85.

11. Nurminen MM, Heathcote CR, Davis BA. Estimating marginal cohort working life expectancies from cross-sectional surveys. J Off Stat 2004;20:495-517.

12. Nurminen MM, Heathcote CR, Davis BA. Estimating conditional work life expectancies from aggregate cohort data. Internet J Epidemiol 2004;1(2).

13. Nurminen MM, Heathcote CR, Davis BA, Puza BD. Working life expectancies: the case of Finland 1980-2001. J Roy Stat Soc Ser A 2005;168(3). In press.

14. Davis BA, Heathcote CR, O'Neill TJ. Estimating cohort health expectancies from cross-sectional surveys of disability. Stat Med 2001;20:1097-111.

15. Davis BA, Heathcote CR, O'Neill TJ. Estimating and interpolating a Markov chain from aggregate data. Biometrika 2002;89:95-110.

16. Sullivan DF. A single index of mortality and morbidity. HSMHA Health Rep 1971;86:347-54.

17. Hoem JM. A Markov chain model of working life tables. Scand Actuarial J 1977;77:1-20.

18. Hoem JM. Life table analysis. In: Armitage P, Colton T, editors. Encyclopedia of Biostatistics. New York (NY): John Wiley \& Sons, Inc; 1988. p 2235-9.
19. Mathers CD. Health expectancies: an overview and critical appraisal. In: Murray CJL, Salomon JA, Mathers CD, Lopez $\mathrm{AD}$, editors. Summary measures of population health: concepts, ethics, measurement and application. Geneva: World Health Organization; 2000. p 177-204.

20. Mathers CD, Robine JM. How good is Sullivan's method for monitoring changes in population health? J Epidemiol Community Health 1997;51:80-6.

21. Schoen R, Woodrow K. Labor force status life tables for the United States, 1972. Demography 1980;17:297-322.

22. Smith SJ. Tables of working life: the increment-decrement model: bulletin 2135 (February). Washington (DC): US Department of Labor, Bureau of Labor Statistics; 1982.

23. Willekens FJ. Multistate analysis: tables of working life. Environ Planning 1980;12:563-88.

24. Cambois EJ, Robine M, Brouard N. Life expectancies applied to specific statuses: a history of the indicators and the methods of calculation. Popul En Sel 1999;11:7-34.

25. Hayward MD, Grady WER. Work and retirement among a cohort of older men in the United States, 1966-1983. Demography 1990;27:337-56.

26. Land KC, Guralnik JM, Blazer DG. Estimating incrementdecrement life tables with multiple covariates from panel data: the case of active life expectancy. Demography 1994;31:297319.

27. Richards H, Abele J. Life and work expectancies. Tucson (AZ): Lawyers and Judges Publishing Company; 1999.

28. Crimmins EM, Hayward MD, Saito Y. Differential in active life expectancy in the older population of the United States. J Gerontol Soc Sci 1996;51B:S109-20.

29. Hayward MD, Friedman S, Chen H. Race inequality in men's retirement. J Gerontol Soc Sci 1996;51B:S1-10.

30. Hayward MD, Lichter DT. A life cycle model of labor force inequality: extending Clogg's life table approach. Sociolog Methods Res 1998;26:487-510.

31. Citro F, Hanushek EA. Improving information for social policy decisions: the uses of microsimulation modeling; vol 1 (review and recommendations). Washington (DC): National Academy Press; 1991.

32. Laditka SB, Wolf DA. New methods for analyzing active life expectancy. J Aging Health 1998;10:214-41.

33. Van Imhoff E, Post W. Microsimulation methods for population projection. Popul En Sel 1998;19(1 special issue):97138.

34. Ciecka J, Donley T, Goldman J. A Markov process model of work-life expectancies based on labor market activity in 199293. J Leg Econ 1995(Winter):17-41.

35. Liang KY, Zeger SL. Longitudinal data analysis using generalised linear models. Biometrika 1986;73:13-22.

36. Wolf DA, Laditka SB. Stochastic modeling of active life and its expectancy. Syracuse (NY): Maxwell Centre for Demography and Economics of Aging; 1997. Papers in Microsimulation Series, paper no 4.

37. Brunsdon TM, Smith TMF. The time series analysis of compositional data. J Off Stat 1998;14(3);237-53.

38. Heligman L, Pollard JH. The age pattern of mortality. J Inst Actuaries 1980;107:49-75.

39. Kostaki A. A nine parameter version of the Heligman-Pollard formula. Math Popul Stud 1992;3:277-88.

40. Heathcote CR, McDermid IM. Projections of cohort life expectancy based on weighted least squares methods. In: Mathers C, McCallum J, Robine J-M, editors. Advances in health expectancies. Canberra (Australia): Australian Institute of Health and Welfare; 1994. p 96-114. 
41. Heathcote CR, Davis BA, Puza BD, O'Neill TJ. The health expectancies of older Australians. J Popul Res 2003;20:109_ 85.

42. Hoem JM, Funck Jensen U. Multistate life table methodology: a probabilistic critique. In: Land KL, Rogers A, editors. Multidimensional mathematical demography. New York (NY): Academic Press; 1982. p 155-264.

43. Schoen R, Land KC. A general algorithm for estimating a Markov-generated increment-decrement life table with application to marital-status patterns. J Am Stat Assoc 1979;74:761-76.

44. Ledent J. Transition probability estimation in increment-decrement life tables using mobility data from a census or survey. In: Land KC, Rogers A, editors. Multidimensional mathematical demography. New York (NY): Academic Press; 1982. p 347-84.

45. Cox DR. Regression models and life-tables (with discussion). J Roy Stat Soc B 1972;34:187-220.

46. Gill RD. Multistate life tables and regression models. Math Popul Stud 1992;3:259-76.

47. Nurminen M. Working population health metrics [review]. Scand J Work Environ Health 2004;30(5):339-49.

48. Guilkey DK, Rindfuss RR. Logistic regression multivariate life tables. Soc Meth Res 1987;16:276-300.

49. Gill RD, Keilman N. The estimation of multidimensional demographic models with population registration data. Math Popul Stud 1990;2:119-43.

50. Land KC, Schoen. Statistical methods for Markov-generated increment-decrement life tables with polynomial gross flow functions. In: Land KC, Rogers A, editors. Multidimensional mathematical demography. New York (NY): Academic Press; 1982. p 265-346.

51. Wamala S, Ågren G. Gender inequality and public health. Eur J Public Health 2002;12:163-5.

52. Macintyre S, Hunt K, Sweeting H. Gender differences in health: are things really as simple as they seem? Soc Sci Med 1996;42:617-24.

53. Hytti H. Active and retirement life expectancy in Finland. Yearb Popul Res Finl 1996;33:207-17.

54. Finnish Centre for Pensions, Social Insurance Institution. Statistical yearbook of pensioners in Finland 2002. Helsinki: Finnish Centre for Pensions, Social Insurance Institution;
2003.

55. Gould R, Nyman H. Työkyvyttömyyseläkkeet 1990-2001 [Disability pensions in 1990-2001]. Helsinki: The Finnish Centre for Pensions; 2002. Paper 38.

56. Karisalmi S. Työn vaatimukset, työkeskeisyys ja ajatukset varhaisesta eläkkeellesiirtymisestä [Demands of work, work centricity and thoughts about early retirement]. In: Tuomi K, editor. Yrityksen menestyminen ja henkilöstön hyvinvointi [The success of an enterprise and the well-being of the personnel]. Helsinki: Finnish Institute of Occupational Health; 2000. Työ ja ihminen [People and Work], research report 15:62-73.

57. Macfarlane I. An address to the Pursuing Opportunity \& Prosperity 2003 Economic and Social Outlook Conference in Melbourne, November 13, 2003 [extract]. The Australian 2003 November 14, p 1.

58. Organisation for Economic Co-operation and Development (OECD). OECD economic surveys Finland. Paris: OECD; 2002.

59. Lindell C. Longevity is increasing — what about the retirement age? Helsinki: Finnish Centre for Pensions (FCP); 2004. FCP working papers 6 .

60. Bank of Finland. The Bank of Finland's macroeconomic forecast 2003-2005. Bank Finland Bull 2003;77(1).

61. Evans K. The effects of ageing and education on the economic dependency ratio in Finland [dissertation]. Helsinki: Department of Sociology, Faculty of Social Sciences, University of Helsinki; 2002. [See: http://www.valt.helsinki.fi/gradutmp/ g1863.htm (accessed on March 10, 2005).]

62. OECD (Organisation for Economic Co-operation and Development). OECD economic surveys Finland. Paris: OECD; 2002.

63. Kannisto J. Effective retirement age in the earnings-related pension scheme in 1996-2003. Helsinki: Finnish Centre for Pensions; 2004. Working papers 8.

64. Sosiaali- ja terveysministeriö (STM) [Ministry of Health and Social Affairs]. Sosiaali- ja terveyspolitiikan strategiat 2010 kohti sosiaalisesti kestävää ja taloudellisesti elinvoimaista yhteiskuntaa [The strategies of social and health politics 2010toward a socially sustainable and economically viable society]. Helsinki: STM; 2001. STM:n julkaisuja 2001:3.

Received for publication: 16 November 2004 